2021 Feb 10;9:632914. doi: 10.3389/ fpubh.2021.632914. PMID: 33643995; PMCID: PMC7902782.

6. Malik AA, McFadden SM, Elharake J, Omer SB. Determinants of COVID-19 vaccine acceptance in the US. EClinicalMedicine. 2020 Sep;26:100495. doi: 10.1016/j.eclinm.2020.100495. Epub 2020 Aug 12. PMID: 32838242; PMCID: PMC7423333.

7. Wang J, Jing R, Lai $X$, Zhang $H$, Lyu $Y$, Knoll MD, Fang H. Acceptance of COVID-19 Vaccination during the COVID-19 Pandemic in China. Vaccines (Basel). 2020 Aug 27;8(3):482. doi: 10.3390/vaccines8030482. PMID:

32867224; PMCID: PMC7565574.

8. Yuan Liang Woon and al. Factors influencing acceptance of COVID-19 vaccination among Malaysian adults, August 2020, National Conference for Clinical Research DOI: $10.13140 /$ RG.2.2.32024.62728

9. Bono, Suzanna Awang et al. "Factors Affecting COVID-19 Vaccine Acceptance: An International Survey among Low- and Middle-Income Countries." Vaccines vol. 9,5 515. 17 May. 2021, doi:10.3390/vaccines 9050515

\title{
PHÂN TÍCH MộT SỐ YẾU TỐ LIÊN QUAN ĐẾN TỬ VONG Ở BỆNH NHÂN NHỒI MÁU NÃO CẤP TÍNH DIỆN RộNG CÓ ĐẠTT NộI KHÍ QUẢN
}

\section{TÓM TẮT}

Mục tiêu: Phân tích một số yếu tố liên quan đến tử vong ở bênh nhân nhồi máu não cấp tính diên rông có đăt nội khí quản (NKQ). Đối tượng nghiên cứu: 69 bệnh nhân nhồi máu não cấp tính diện rộng, trong đó 38 bệnh nhân không đặt NKQ, 31 bệnh nhân có đăt NKO điều tri tai Trung tâmthần kinh Bênh viên Bạch Mai từ tháng 8/2020-7/2021. Phương pháp nghiên cứu: Mô tả cắt ngang. Kết quả: Tuổi trung bình của nhóm bênh nhân có đă̆t NKQ là $70,32 \pm 11,37$, nam giới chiếm $67,7 \%$, tỷ lề tử vong là $41,9 \%$, điểm NIHSS trung bình khi nhập viện là $21,81 \pm 3,53$, điểm Glasgow lúc nhâp viên là $11,87 \pm 1,15$. Các triệu chứng lâm sàng khi khởi phát nổi bât hơn ở nhóm có đă̆t NKQ bao gồm: đau đâu $(48,1 \%)$, rối loạn ý thức $(90,3 \%)$, quay mắt quay đầu $(77,4 \%)$, rối loạn cơ tròn $(74,2 \%)$, với $p<0,05$. Lý do đặt nội khí quản do nguyên nhân thần kinh chiếm 80,6\%; điểm Glasgow trung bình khi đặt nôi khí quản

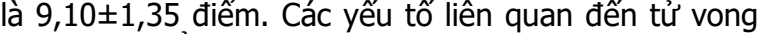
bao gồm: điểm NIHSS lúc nhập viện, đặt nội khí quản do nguyên nhân thần kinh, điểm Glasgow lúc đặt nội khí quản, bất thường kích thước đồng tử và mất PXAS đồng tử lúc đặt nội khí quản, mức độ di lệch đường giữa trên hình ảnh học. Kết luận: Tỷ lệ tử vong ở nhóm bênh nhân nhồi máu não cấp tính diện rộng có đặt nội khí quản là 41,9\%. Các yểu tố liên quan đến tử vong bao gồm: điểm NIHSS lúc nhâp viên, đăt nôi khí quản do nguyên nhân thần kinh, điểm Glasgow lúc đătt nội khí quản, bất thường kích thước đồng tử và mất PXAS đồng tử lúc đặt nội khí quản, mức độ di lệch đường giữa trên hình ảnh học. Tư khóa: Nhồi máu não diện rộng, nội khí quản, tử vong.

${ }^{1}$ Bệnh Viện Đa khoa Của Đông - Nghệ An

2Trường đại họ Y Hà Nội

${ }^{3}$ Bênh viên Bach Mai

Chịu trách nhiệm chính: Nguyễn Văn Quân

Email: bsquantk@gmail.com

Ngày nhận bài: 17.5.2021

Ngày phản biên khoa hoc: 2.7.2021

Ngày duyệt bài: 19.7.2021
Nguyễn Văn Quân ${ }^{1}$, Võ Hồng Khôi ${ }^{2,3}$

SUMMARY

ANALYSIS OF SOME FACTORS RELATED TO

MORTALITY IN PATIENTS WITH ACUTE

LARGE HEMISPHERIC INFARCTION WITH

ENDOTRACHEAL INTUBATION

Background: Analysis of some factors related to mortality in patients with acute large hemispheric infaection with endotracheal intubation. Method: Study of69 patients with acute large hemispheric infaection, of which 38 patients without the intubation and 31 patients with the intubation, were treated in Neurological Center of Bach Mai Hospital from August 2020 to July 2021. Result: The average age of patients with the intubation was $70.32 \pm 11.37$, male $69.2 \%$, mortality rate $41,9 \%$. The mean of NIHSS score at hospital admission was $21.81 \pm 3.5$. The mean of Glasgow score at hospital admission was $11.87 \pm 1.15$. Clinical symptomonset was more prominent in the group with the intubation including: headache $(48.1 \%)$, consciousness disorders $(90.3 \%)$, head-eye deviation (77.4\%), urinary incontinenceonset $(74.2 \%)$, with $p<0.05$. Reason for the intubation due to neurological causes accounted for $80.6 \%$; The mean Glasgow score at intubation was $9.10 \pm 1.35$ points. Factors related to the mortality included: NIHSS score at hospital admission, endotracheal intubation due to neurological causes, Glasgow score at the intubation, dilated pupi admission and loss of light reflection at the intubation, midline shift. Conclusion: The mortality rate in the group of patients with acute large hemispheric infaection with the intubation was $41.9 \%$. Factors related to the mortality included: NIHSS score on admission, neurogenic reason for intubation, Glasgow score at intubation, dilated pupil admission and loss of light reflection at the intubation, midline shift

Keywords; Acute large hemispheric infaection, endotracheal intubation, morality.

\section{I. ĐĂT VẤN ĐỀ}

Đột quy não là vấn đề thời sự cấp thiết trên toàn câu, là nguyên nhân tử vong đứng hàng 
thứ ba, tàn phế đứng hàng thứ nhất. Ở Việt Nam trong những năm gần đây, những tiến bộ trong điêu trị nội khoa cũng như các phương pháp can thiệp trong giai đoạn cấp đối với bênh nhân nhồi máu não đã giúp cải thiện đáng kể tỷ lệ tử vong và tàn phế. Tuy nhiên, với các bệnh nhân nhồi máu não diện rộng, diện tổn thương lớn, lâm sàng thường nặng nề, có thể kèm theo rối loạn ý thức, mất khả năng bảo vệ đường thở, ùn tắc đờm dãi, hoặc có thể suy hô hấp do ảnh hưởng trung khu hổ hấp hay do các bệnh lý tim phổi. Việc đặt nội khí quản cho những bệnh nhân này là cần thiết để hố trợ hô hấp, bảo vệ đường thở, đảm bảo cung cấp oxy đầy đủ cho tế bào não. Mặc dù tỉ lệ bệnh nhân nhồi máu não phải đặt nội khí quản không cao (10-16\%) nhưng tiên lượng lại rất xấu, di chứng thần kinh nặng nề, tỷ lệ tử vong cao (40-70\%) ${ }^{1}$. Việc xác định các yếu tố liên quan đến tử vong ở bềnh nhân nhồi máu não diện rộng có đăt nội khí quản là cần thiết trong thực hành lâm sàng, cung câp thêm các thông tin giúp bác sĩ tiên lượng sớm nguy cơ tử vong của bệnh nhân. Vì vậy, chúng tôi tiến hành nghiên cứu đề tài với mục tiêu:

1. So sánh môt số đặc điểm lâm sàng, hinh ảnh học ở bệnh nhân nhồi máu não cấp tính diện rộng có đặt NKQ và không đặt NKQ.

2. Phần tích một số yếu tố liên quan đến tử vong ở bệnh nhân nhồi máu não cấp tính diện rộng có đặt NKQ.

\section{II. ĐỐI TƯợNG VÀ PHƯƠNG PHÁP NGHIÊN CỨU 2.1 Đối tượng nghiên cứu}

\section{KẾT QUẢ NGHIÊN CứU}

\section{1 Đặc điểm chung nhóm nghiên cứu}

Bảng 3.1 Đặc điểm chung nhóm nghiên cứu

\begin{tabular}{|c|c|c|c|c|c|c|}
\hline \multirow{2}{*}{\multicolumn{2}{|c|}{ Đặc điểm chung }} & \multicolumn{2}{|c|}{ Không đặt NKQ } & \multicolumn{2}{|c|}{ Có đặt NKQ } & \multirow[b]{2}{*}{$\mathbf{p}$} \\
\hline & & Số BN & Tỷ lệ (\%) & Số BN & Tỷ lệ (\%) & \\
\hline \multirow[b]{2}{*}{ Giới } & Nam & 21 & $55,3 \%$ & 21 & $67,7 \%$ & \multirow[b]{2}{*}{$>0,05$} \\
\hline & Nữ & 17 & $44,7 \%$ & 10 & $32,3 \%$ & \\
\hline \multirow{2}{*}{\multicolumn{2}{|c|}{ Tuối trung bình (năm) }} & \multicolumn{2}{|c|}{$66,84 \pm 11,78$} & \multicolumn{2}{|c|}{$70,32 \pm 11,37$} & $>0,05$ \\
\hline & & \multicolumn{2}{|c|}{$18,05 \pm 13,32$} & \multicolumn{2}{|c|}{$15,06 \pm 10,64$} & $>0,05$ \\
\hline
\end{tabular}

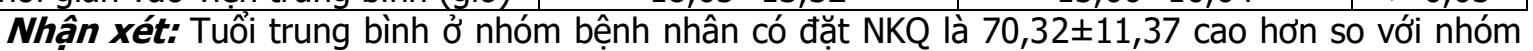
không đặt NKQ66,84 $\pm 11,78, p>0,05$. Tỷ lệ bệnh nhân nam của nhóm có đặt NKQ và không đặt NKQ lần lượt là $67,7 \%$ và $55,3 \%$.

3.2 Đặc điểm lâm sàng và hình ảnh học nhóm nghiên cứu

Bảng 3.2 Đặc điểm lâm sàng và hình ảnh học nhóm nghiên cứu

\begin{tabular}{|c|c|c|c|c|c|}
\hline \multirow{2}{*}{ Đặc điểm lâm sàng } & \multicolumn{2}{|c|}{ Không đặt NKQ } & \multicolumn{2}{|c|}{ Có đặt NKQ } & \multirow{2}{*}{ p } \\
\cline { 2 - 5 } & Số BN & Tỷ lệ (\%) & Số BN & Tỷ lệ (\%) & (\%,008 \\
\hline Đau đầu khi khởi phát & 6 & $15,8 \%$ & 15 & $48,1 \%$ & $\mathbf{0 , 0 0}$ \\
\hline RL ý thức khi khởi phát & 14 & $36,8 \%$ & 28 & $90,3 \%$ & $<\mathbf{0 , 0 0 1}$ \\
\hline RL ngôn ngữ khi khởi phát & 36 & $94,4 \%$ & 31 & $100 \%$ & $>0,05$ \\
\hline RL cơ tròn khi khởi phát & 10 & $26,3 \%$ & 23 & $74,2 \%$ & $<0,001$ \\
\hline
\end{tabular}




\begin{tabular}{|c|c|c|c|c|c|}
\hline Quay mắt quay đâu & 8 & $21,4 \%$ & 24 & $77,4 \%$ & $<0,001$ \\
\hline Điểm Glasgow lúc vào viện & \multicolumn{2}{|c|}{$13,74 \pm 0,86$} & \multicolumn{2}{|c|}{$11,87 \pm 1,15$} & $<0,001$ \\
\hline Điểm NIHSS lúc vào viện & \multicolumn{2}{|c|}{$16,68 \pm 2,23$} & \multicolumn{2}{|c|}{$21,81 \pm 3,53$} & $<0,001$ \\
\hline Điếm ASPECT vào viện & \multicolumn{2}{|c|}{$4,76 \pm 0,97$} & \multicolumn{2}{|c|}{$4,39 \pm 1,15$} & $>0,05$ \\
\hline Đè đấy đường giữa (mm) & \multicolumn{2}{|c|}{$2,39 \pm 2,68$} & \multicolumn{2}{|c|}{$7,03 \pm 3,83$} & $<0,001$ \\
\hline Chuyến dạng chảy máu & 3 & $7,9 \%$ & 14 & $45,2 \%$ & 0,001 \\
\hline
\end{tabular}

Nhận xét: Triệu chứng lâm sàng lúc khời phát của nhóm bệnh nhân nghiên cứu rất đa dạng, trong đó các triệu chứng nổi bật hơn ở nhóm có đặt NKQ bao gồm: đau đầu, rối loạn ý thức, quay mắt quay đầu, rối loạn cơ tròn. Điểm Glasgow lúc vào viện của nhóm có đặt NKQ là $11,87 \pm 1,15$ thấp hơn so với nhóm không đặt NKQ13,74 $00,86, p<0,001$; điểm NIHSS của nhóm có đặt NKQ là $20,88 \pm 3,66$ cao hơn với nhóm không đặt NKQ, $p<0,001$. Các đặc điểm hình ảnh học có sự khác biệt giữa hai nhóm với $p<0,05$ bao gồm: đè đầy đường giữa và chuyển dạng chảy máu. Điểm ASPECT

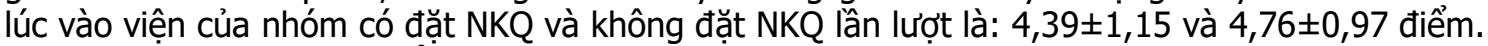

Bảng 3.3 Các đặc điểm lâm sàng liên quan đến đặt NKQ

Đặc điểm lâm sàng liên quan đến đặt NKQ

\begin{tabular}{|c|c|c|c|}
\hline \multicolumn{2}{|c|}{ Đặc điểm lâm sàng liên quan đến đặt NKQ } & Số BN & Tỷ lệ \% \\
\hline \multirow{2}{*}{ Nguyên nhân đặt NKQ } & Nguyên nhẩn thần kinh & 25 & $80,6 \%$ \\
\cline { 2 - 4 } & Nguyên nhân hô hấp & 6 & $19,4 \%$ \\
\hline \multicolumn{2}{|c|}{ Thời điểm đặt NKQ (ngày) } & \multicolumn{2}{|c|}{$2,77 \pm 1,41$} \\
\hline \multicolumn{2}{|c|}{ Điểm Glasgow lúc đă̆t NKQ } & 16 & $51,6 \%$ \\
\hline \multicolumn{2}{|c|}{ Bất thường kích thước đồng tử } & 11 & $35,5 \%$ \\
\hline \multicolumn{2}{|c|}{ Mất phản xạ ánh sáng đồng tử }
\end{tabular}

Nhân xét: Lý do đặt NKQ ở nhóm nghiên cứu phần lớn do nguyên nhân thần kinh: $80,6 \%$. Thời

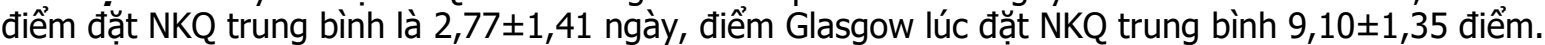

3.4 Một số yếu tố liên quan đến tử vong ở bệnh nhân nhồi máu não cấp tính diện rộng Có đặt NKQ.

Bảng 3.4 Liên quan giữa đặc điểm lâm sàng và kêt cục tử vong

\begin{tabular}{|c|c|c|c|c|c|}
\hline \multirow{2}{*}{ Đặc điểm lâm sàng } & \multicolumn{2}{|c|}{ Sống } & \multicolumn{2}{|c|}{ Tử vong } & \multirow[b]{2}{*}{$\mathbf{p}$} \\
\hline & Số BN & Tỷ lệ (\%) & Số BN & Tỷ lệ (\%) & \\
\hline Tuổi & \multicolumn{2}{|c|}{$69,61 \pm 11,20$} & \multicolumn{2}{|c|}{$71,31 \pm 11,99$} & $>0,05$ \\
\hline Điểm Glasgow lúc vào viện & \multicolumn{2}{|c|}{$12,11 \pm 1,08$} & \multicolumn{2}{|c|}{$11,54 \pm 1,20$} & $>0,05$ \\
\hline Điểm NIHSS lúc vào viện & \multicolumn{2}{|c|}{$20,67 \pm 3,23$} & \multicolumn{2}{|c|}{$23,38 \pm 3,40$} & 0,034 \\
\hline Thời điểm đặt NKQ (ngày) & \multicolumn{2}{|c|}{$2,56 \pm 1,20$} & \multicolumn{2}{|c|}{$3,08 \pm 1,66$} & $>0,05$ \\
\hline Điểm Glasgow lúc đặt NKQ & \multicolumn{2}{|c|}{$9,61 \pm 1,01$} & \multicolumn{2}{|c|}{$8,38 \pm 1,39$} & 0,015 \\
\hline Đăt NKQ nguyên nhân thần kinh & 12 & $66,7 \%$ & 13 & $100 \%$ & 0,028 \\
\hline Bất thường kích thước đồng tử lúc đặt NKQ & 5 & $27,8 \%$ & 11 & $84,6 \%$ & 0,006 \\
\hline Mất PXAS đồng tử lúc đặt NKQ & 2 & $11,1 \%$ & 9 & $69,2 \%$ & 0,002 \\
\hline
\end{tabular}

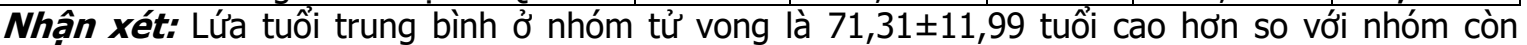

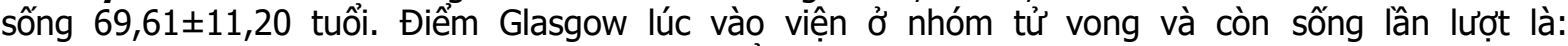
$11,54 \pm 1,20$ và $12,11 \pm 1,08, p>0,05$. Các đặc điểm lẩm sàng có liên quan đến tử vong $(p<0,05)$ bao gồm: Điểm NIHSS lúc vào viện, đặt NKQ nguyên nhân thần kinh, điểm Glasgow lúc đặt NKQ, bất thường kích thước và mất PXAS đồng tử lúc đặt NKQ.

Bảng 3.5 Liên quan giữa đặc điểm hinh ảnh học với kêt cục tử vong

\begin{tabular}{|c|c|c|c|c|c|}
\hline \multirow{2}{*}{ Đặc điểm hình ảnh học } & \multicolumn{2}{|c|}{ Sống } & \multicolumn{2}{|c|}{ Tử vong } & \multirow[b]{2}{*}{$\mathbf{p}$} \\
\hline & Số BN & Tỷ lê (\%) & Số BN & Tỷ lê (\%) & \\
\hline Điểm ASPECTS trung bình & \multicolumn{2}{|c|}{$4,67 \pm 1,24$} & \multicolumn{2}{|c|}{$4,00 \pm 0,91$} & $>0,05$ \\
\hline Di lệch đường giữa & \multicolumn{2}{|c|}{$4,67 \pm 1,69$} & \multicolumn{2}{|c|}{$10,31 \pm 3,55$} & 0.001 \\
\hline Chuyển dạng chảy máu & 7 & $38,9 \%$ & 7 & $53,8 \%$ & $>0,05$ \\
\hline
\end{tabular}

Nhận xét: Điểm ASPECT trung bình ở nhóm tử vong và còn sống lần lượt là: $4,00 \pm 0,91$ và $4,67 \pm 1,24$ điểm. Tỷ lệ chuyển dạng chảy máu ở nhóm tử vong cao hơn nhóm còn sống ( $53,8 \%$ so với 38,9\%), sự khác biệt không có ý nghĩa thống kê, $p>0,05$. Riêng mức độ di lệch đường giữa ở nhóm tử vong $(10,31 \pm 3,55 \mathrm{~mm})$ cao hơn rõ rệt so với nhóm còn sống $(4,67 \pm 1,69 \mathrm{~mm})$ có ý nghĩa với $p=0,001$. 


\subsection{Kết quả điêu trị ở nhóm bệnh nhân có đặt NKQ}

Kết quả điều trị

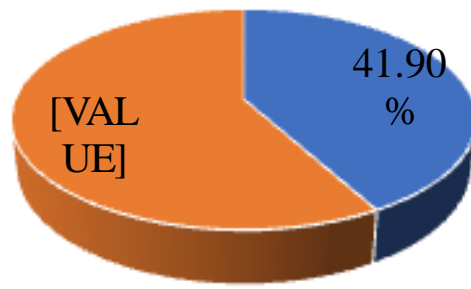

- Tử vong " Còn sống

\section{Biểu đồ 3.1 Kêt quả điều trị ở nhóm bênh} nhân có đă̆t NKQ

Nhân xét: Tỷ lệ tử vong ở nhóm bệnh nhân có đặt NKQ còn cao: 41,9\%.

\section{BÀN LUÂ̂N}

Tuổi trung bình ở nhóm bệnh nhân có đặt NKQ là 70,32 211,37 tuổi, cao hơn kết quả nghiên cứu của Eva Schielke và cộng sự $(63,8 \pm 12,4 \text { tuổi })^{2}$ và nghiên cứu của Berrouschot và cộng sự $(63 \pm 13)^{3}$. Nam giới chiếm $67,7 \%$ và không có sự khác biệt về tỷ lệ tử vong giữa hai giới nam và nữ, $p>0,05$. Tỷ lể tử vong ở nhóm bệnh nhân có đặt NKQ là 41,9\%, kết quả này tương tự kết quả nghiên cứu của Francois Santoli và cộng sự $(40,5 \%$ bệnh nhân tử vong trong tuần đầu tiên khi nhập viện, $72,4 \%$ bệnh nhân tử vong sau 1 năm $)^{1}$.

Triệu chứng lâm sàng ở bệnh nhân nhồi máu não diện rộng rất đa dạng, trong nghiên cứu của chúng tôi, các triệu chứng lâm sàng lúc khởi phát nổi bật hơn ở nhóm có đặt NKQ bao gồm: đau đầu $(48,1 \%)$, rối loạn ý thức $(90,3 \%)$, quay mắt quay đầu $(77,4 \%)$ và rối loạn cơ tròn $(74,2 \%)$. Điểm Glasgow lúc nhập viện ở nhóm có đặt NKQ là $11,87 \pm 1,15$ thấp hơn nhóm không đặt NKQ là $13,74 \pm 0,86, p<0,001$. Nghiên cứu của Gupta và cộng sự (2014), điểm Glasgow nhóm bệnh nhân nhồi máu não có đặt NKQ là 7,445 $\pm 3,4$ và nhóm không không đặt NKQ là 13,98 \pm 2,139 $(p<0,05)^{4}$. Điểm NIHSS ở nhóm có đặt NKQ cao hơn rõ rêt so với nhóm không đặt NKQ $(21,42 \pm$ 3,43 so với $17,14 \pm 2,29$ điểm), $p<0,001$.

Chỉ định đặt NKQ do nguyên nhân thần kinh chiếm $80,6 \%$, kết quả này tương tự kết quả nghiên cứu của Eva Schielke và cộng sự $(81 \%)^{2}$ và đặt NKQ nguyên nhân thần kinh là yếu tố liên quan đến tử vong, $p=0,028$. Điểm Glasgow trung bình lúc đặt NKQ ở nhóm tử vong là $8,38 \pm 1,39$, thấp hơn nhóm còn sống là $9,61 \pm 1,01$, điểm Glasgow lúc đặt NKQ là yếu tố liên quan đến tử vong với $p=0,02$. Nhận định này giống với nghiên cứu của Stephan $A$. Mayer và cộng sự (điểm Glasgow lúc đặt NKQ là một yếu tố tiên lượng tử vong với $p=0,03)^{5}$. Tai thời điểm đăt NKQ, ở nhóm tử vong có $84,6 \%$ bệnh nhân có bất thường kích thước đồng tử, 69,2\% bệnh nhân mất PXAS đồng tử, cả hai biểu hiện lâm sàng này đều có liên quan đến kết cục tử vong với $p=0,04$.

Điểm ASPECT trung bình lúc nhập viện ở nhóm bệnh nhân có đặt NKQ thấp hơn nhóm không đă̆t $N K Q$ lần lượt là: $4,35 \pm 1,2$ và $5,04 \pm 1,32$ điểm, $p>0,05$. Mức đô di lêcch đường giữa trên hình ảnh học là một yếu tố liên quan chặt chẽ đến kết cục tử vong, $p=0,001$. Nhận định này phù hợp với kết quả nghiên cứu của Stephan $A$. Mayer và cộng sự ${ }^{5}$, nhưng khác với Brian P.Walcott và cộng sự khi nghiên cứu 46 bệnh nhân nhồi máu động mạch não giữa nghiêm trọng thấy rằng dịch chuyển đường giữa không phải là yếu tố liên quan đến tử vong, $p=0,61^{6}$. Trong nhóm có đặt NKQ, chuyển dạng chảy máu cao hơn ở nhóm tử vong $69,2 \%$ so với $30,8 \%$ ở nhóm còn sống, tuy nhiên chuyển dạng chảy máu không phải là yếu tố liên quan đến kết cục tử vong, $p>0,05$.

\section{KẾT LUÂN}

Bênh nhân nhồi máu não cấp tính diện rộng có đắt NKQ có mức đô tàn tâtt nặng và nguy cơ tử vong cao 41,9\%. Các yếu tố có liên quan đến kết cục tử vong bao gồm: điểm NIHSS lúc nhập viện, đặt NKQ nguyên nhân thần kinh, điểm Glasgow lúc đăt NKQ, bất thường kích thước đồng tử và mất $P X A S$ đồng tử lúc đặt NKQ và mức độ di lệch đường giữa trên hình ảnh học.

\section{TÀI LIÊU THAM KHẢO}

1. Santoli F, De Jonghe $B$, Hayon $J$, et al. Mechanical ventilation in patients with acute ischemic stroke: survival and outcome at one year. Intensive Care Med. 2001;27(7):1141-1146. doi:10.1007/s001340100998

2. Schielke $E$, Busch MA, Hildenhagen $T$, et al. Functional, cognitive and emotional long-term outcome of patients with ischemic stroke requiring mechanical ventilation. J Neurol. 2005;252(6):648654. doi:10.1007/s00415-005-0711-5

3. Berrouschot J, Rössler A, Köster J, Schneider D. Mechanical ventilation in patients with hemispheric ischemic stroke: Critical Care Medicine. 2000;28(8):2956-2961. doi:10.1097/ 00003246-200008000-00045

4. Gupta P, Prasad K, Kumar A, Kumar P, Bhatia $\mathbf{R}$, Tripathi M. Clinical predictors and outcome of patients of acute stroke requiring ventilatory support: A prospective hospital based cohort study. Journal of the Neurological Sciences. 
2014:337(1-2):14-17

doi:10.1016/j.jns.2013.11.007

5. Mayer SA, Copeland D, Bernardini GL, et al. Cost and Outcome of Mechanical Ventilation for Life-Threatening Stroke. Stroke.2000;31(10):2346-
2353. doi:10.1161/01.STR.31.10.2346

6. Walcott BP, Miller JC, Kwon C-S, et al. Outcomes in Severe Middle Cerebral Artery Ischemic Stroke. Neurocrit Care. 2014;21(1):2026. doi:10.1007/s12028-013-9838-x

\section{BộC Lộ DẤU ẤN HÓA MÔ MIỄN DİCH CK20 TRONG UNG THƯ BIỂU MÔ BÀNG QUANG}

\section{TÓM TẮT}

Mục tiêu: Nhận xét một số đặc điểm của dấu ân miễn dịch CK 20 và mối liên quan với độ mô học, giai đoạn trong khối u bàng quang phâuu thuật tại bệnh viện Việt Đức. Đối tượng và phương pháp nghiên cứu: Hồi cứu 99 trường hợp ung thư biểu mô bàng quang qua các mẫu bệnh phẩm phẫu thuật tại bệnh viên Viêt Đức. Kết quả: Dấu ấn CK 20 âm tính với 32 trường hợp (32,3\%); dương tính ổ ( $<10 \%$ tế bào $\mathrm{u}$ ) có 27 trường hợp (27,3\%), dương tính lan tỏa có 40 trường hợp (40,4\%). Dấu ấn CK 20 có mối liên quan với đố mô hoc với $\mathrm{p}=0,000<0,05$ và có mối liên quan với giai đoạn bệnh với $p=0,01<0,05$. Các mối liên quan có ý nghĩa thống kê.

Từ khóa: Ung thư biểu mô bàng quang, CK20.

\section{SUMMARY}

\section{EXPRESSION OF CYTOKERATIN 20 IN}

\section{UROTHELIAL CARCINOMA OF BLADDER}

Objectives To evaluate some features of CK 20 immunomarker and its relationship with histological grade, stage in surgical bladder tumor at Viet Duc hospital. Subjects and research methods: A retrospective study was perform in 99 cases of bladder carcinoma through surgical samples at Viet Duc hospital. Results: CK 20 marker was negative in 32 cases $(32.3 \%)$, focal positive ( $<10 \%$ tumor cells) had 27 cases $(27.3 \%)$, diffusely positive had 40 cases (40.4\%). CK 20 marker was related to histological grade with $\mathrm{p}=0.000<0.05$ and related to disease stage with $p=0.01<0.05$. The relationships are statistically significant.

Keywords; Urothelial carcinoma of bladder, cytokeratin 20.

\section{I. ĐẶT VẤN ĐỀ}

Ung thư biểu mô của đường niệu là tổn thương phổ biến nhất trong số ung thư của hệ tiết niệu, trong đó tập trung tại bàng quang khoảng 90-95\%. Tác giả Nguyễn Phúc Cương và

\footnotetext{
${ }^{1}$ Bệnh viện hữu nghi Việt Tiệp

2 Trường đại hoc Y Hà Nôi

Chịu trách nhiệm chính: Nguyễn Trường Giang

Email: truonggiang16121977@gmail.com

Ngày nhân bài: 17.5.2021

Ngày phản biên khoa hoc: 2.7.2021

Ngày duyệt bài: 15.7.2021
}

\section{Nguyễn Trường Giang1, Nguyễn Văn Hưng²}

Nguyễn Sỹ Lánh cho rằng ung thư biểu mô bàng quang chiếm $81,2 \%$ khối u của hệ tiết niệu [1]. Tổ chức y tế thế giới năm 2016 cho biết đây là loại ung thư đứng thứ 7 trong các loại ung thư và chiếm $3,2 \%$ tổng số ca ung thư. Ước tính khoảng 70-80\% bệnh nhân mới chẩn đoán ung thư bàng quang hiện tại với giai đoạn không xâm lấn hoặc đầu xâm lấn (giai đoạn Ta, Tis, hoặc T1) [2]. Cùng với việc phát hiện sớm và định típ mô bênh học thì các yếu tố tiên lượng phân tử của khối u cũng có giá trị cho việc đánh giá mức độ tái phát hay tiến triển của bệnh. Dấu ấn CK20 chỉ dương tính ở lớp tế bào bề mặt hoặc một vài tế bào trung gian của lớp biểu mô bình thường. Khi mức độ bộc lộ vượt quá các giới hạn trên thì có thể gợi ý ung thư biểu mô đường niệu tiến triển, vì trong khối u này dấu ấn CK20 dương tính ở toàn bộ biểu mô của khối u. Chúng tôi nghiên cứu để tài này với mục tiêu: Đánh giá tinh trạng bộc lộ dấu ấn miến dịch CK20 và đối chiêu với typ mô học, độ mô học và giai đoạn bệnh trong ung thư biểu mô niệu bàng quang.

\section{II. ĐỐI TƯỢNG VÀ PHƯƠNG PHÁP NGHIÊN CỨU}

2.1. Đối tượng nghiên cứu. Đối tượng là 99 bệnh nhân UTBQ được cắt bỏ toàn bộ bàng quang chứa u và vét hach, có hồ sơ bênh án và các khối nến lưu trữ tai khoa giải phẫu bênh bệnh viện Hữu Nghị Việt Đức từ tháng 1/2018 đến tháng 3/2019.

\subsubsection{Tiêu chuẩn lựa chọn}

- Các trường hợp phẫu thuật cắt bỏ toàn bộ bàng quang và được chẩn đoán mô bệnh học ung thư biểu mô đường niệu.

- Còn tiêu bản thường quy và khối nến, trong đó, khối nến bệnh phẩm được lưu trữ tốt và còn đủ bệnh phẩm để có thể làm bổ sung xét nghiệm hóa mô miễn dịch.

- Các trường hợp nghiên cứu có hồ sơ bệnh án đủ các thông tin hành chính.

2.1.2. Tiêu chuẩn loại trừ

- Ung thư thứ phát xâm lấn vào bàng quang.

- Ung thư biểu mô đường niệu tái phát. 